\title{
Physiological and pathobiological significance of ocular glycoproteins. I. Studies using fluorescein labelled glycine max
}

\author{
A I AHMED AND A H S RAHI \\ From the Department of Pathology, Institute of Ophthalmology, 17/25 Cayton Street, London EC1V 9AT
}

SUMmaRY Cell surface carbohydrates play an important role in several biological, immunological, and neoplastic phenomena including development, growth regulation, cellular locomotion, receptor activation, and tumour metastasis. Fluorescein labelled lectins which bind to specific carbohydrate residues in glycoproteins and glycolipids are being increasingly used as chemical probes to study cell components. Several different preparations of ocular tissues from human, rabbit, and rat were examined for the distribution of N-acetyl-D-galactosamine (D-gal NAc) by means of fluorescein-labelled lectin from soybean (glycine max). A very strong fluorescence was observed in the corneal epithelium; Descemet's membrane and corneal endothelium were also strongly fluorescent. The conjunctival epithelium similarly showed a strong reaction, as did the goblet cells. The iris epithelium and the dilator pupillae were only weakly fluorescent, but the ciliary body showed strong fluorescence, as did the blood vessels. As compared with lens fibres the lens epithelium was strongly fluorescent. The outer retina, that is, the photoreceptors, the pigment epithelium, and Bruch's membrane, showed a very strong reactivity. The optic nerve showed moderate fluorescence, but reaction with extraocular muscles was variable. The skin of the upper and lower eyelids, hair follicles, and blood vessels showed strong lectin binding. Sections of retinoblastoma and malignant melanoma showed no reaction. The physiological and pathological significance of these findings is discussed.

\begin{abstract}
About $5 \%$ of mammalian cell membrane consists of carbohydrates which are usually associated with glycoproteins, and it is widely recognised that these determine the 'individuality' of a cell and regulate its behaviour, growth, division, and differentiation. Glycoproteins also constitute the antigenic determinants in a given tissue, act as receptors for hormones, mitogens, drugs, and micro-organisms, and provide markers of cellular identity.' Furthermore, cells recognise and interact with each other through surface glycoproteins, sugars acting as a method for cellular communication. The activity of the corneal endothelium, the ciliary epithelium, the photoreceptors, and the retinal pigment epithelium depends on the influx of certain ions and nutrients and eflux of other ions and metabolites, which in turn are dependent on cell surface glycoproteins.

Our understanding of cellular glycoproteins has greatly increased since the discovery of lectins, which Correspondence to Dr A I Ahmed.
\end{abstract}

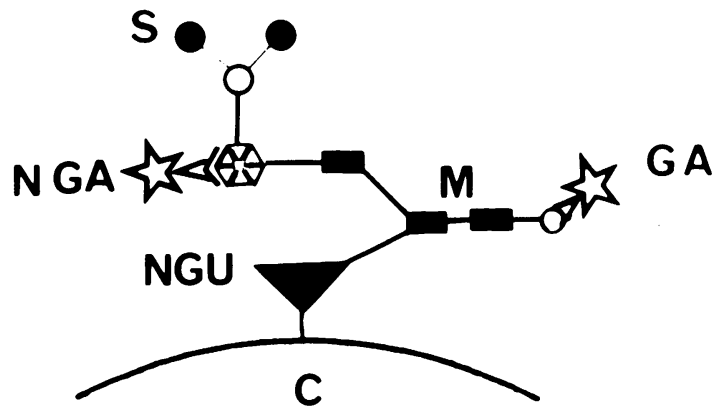

Fig. 1 A typical oligosaccharide sequence in the glycoproteins of cellular surface (c) is illustrated. The stars represent fluorescein labelled lectin. Glycine max binds predominantly to NGA and to a less extent to galactose moiety. $M=$ Mannose. $N G A=N$-acetyl galactosamine. $G A=$ Galactose. $N G U=N$-acetyl glucosamine. $S=$ Sialic acid. 


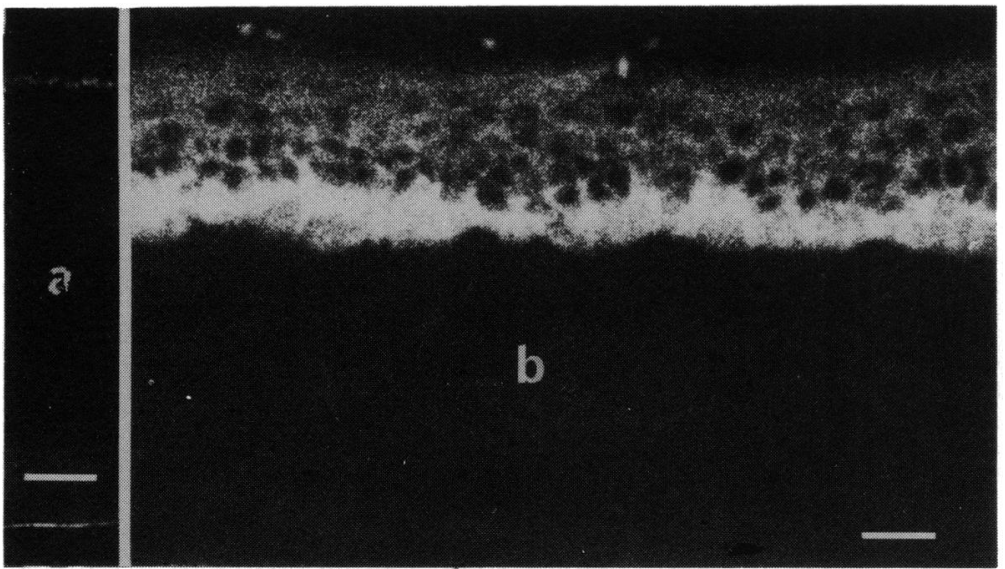

Fig. 2 Normal rabbit cornea stained with fluorescein-labelled soyabean lectin. (a) The epithelium at the top and the endothelium at the bottom of the microphotograph are fluorescent. Bar $=25 \mu \mathrm{m}$. (b) Higher magnification of the epithelial layer showing band-like fluorescence of the basal epithelium. Bar $=10 \mu \mathrm{m}$.

bind in vitro to carbohydrate moieties. Lectins are themselves proteins or glycoproteins and are derived from a wide variety of plants and animals. When labelled with fluorescein or other markers, these can be used to detect specific sugars in a given tissue. Since soybean lectin (glycine max) binds primarily to $\mathrm{N}$-acetyl-D-galactosamine (D-gal NAc) residues in glycoproteins and glycolipids (Fig. 1), it has been advantageously used in the present study to examine the distribution and pathophysiological implication of this sugar in ocular tissues.

\section{Materials and methods}

Various normal and pathological tissues from human, rabbit, and rat eyes were processed for microscopical examination; small strips $5 \times 5 \times 5 \mathrm{~mm}$ were used. Tissues were fixed by immersion in a fixative; variation of the fixation methods included different immersion times (30 min to overnight) and several types of fixative-for example, $2.5 \%$ glutaraldehyde, $10 \%$ paraformaldehyde, $10 \%$

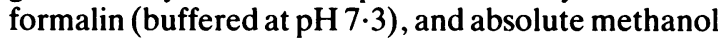
(analytical grade). After being washed in three changes of phosphate buffered saline (PBS), $\mathrm{pH} 7 \cdot 3$, for 30 minutes the specimens were dehydrated in graded methanol, cleared in cedar wood oil (British Drug Houses) with at least three changes, and embedded in paraffin wax. Sections $8 \mu \mathrm{m}$ thick were prepared on a sledge microtome.

The introduction of cedar wood oil as clearing agent and paraffin as embedding material ${ }^{2}$ has greatly simplified fluorescence microscopy of ocular tissues. Fluorescein isothiocyanate (FITC) labelled conjugates (Sigma Chemical Co.) were used in this study ( $2 \%$ in (PBS) for 10 minutes). According to the manufacturers the FITC-lectin conjugates were free of unbound fluorescein and were tested for their agglutinating reactivity on rabbit and human red
Table 1 Demonstration of saccharide binding sites in ocular tissues by means of fluoresceinated lectin

\begin{tabular}{|c|c|}
\hline FITC lectin & Glycine max \\
\hline Sugar & $D-g a l ~ N A C$ \\
\hline \multicolumn{2}{|l|}{ Conjunctiva: } \\
\hline cpithclium & ++ \\
\hline goblet cclls & $++t$ \\
\hline \multicolumn{2}{|l|}{ Cornca: } \\
\hline cpithclium & $++t$ \\
\hline Bowman's zone & + \\
\hline stroma & + \\
\hline Descemet's membranc & ++ \\
\hline endothclium & +++ \\
\hline Sclera & + \\
\hline \multicolumn{2}{|l|}{ Uvca: } \\
\hline iris cpithclium & - \\
\hline ciliary body cpithclium & ++ \\
\hline choroid & + \\
\hline trabccular meshwork & + \\
\hline \multicolumn{2}{|l|}{ Lens: } \\
\hline cpithclium & +++ \\
\hline capsulc & + \\
\hline fibres & ++ \\
\hline \multicolumn{2}{|l|}{ Retina: } \\
\hline pigment cpithclium & $++t$ \\
\hline photoreccptors & $+t+$ \\
\hline ganglion cclls & + \\
\hline others & - \\
\hline Optic nerve & + \\
\hline
\end{tabular}

Table 2 Demonstration of saccharide binding sites in adnexal tissues of the eye by means of FITC lectin

\begin{tabular}{ll}
\hline FITClectin & Glycine max \\
Sugar & D-gal NAC \\
Eyclid: & +++ \\
$\quad$ cpidcrmis & ++ \\
$\quad$ hair folliclc & ++ \\
swcat gland & + \\
schaccous gland & + \\
$\quad$ meibomian gland & + \\
Lacrimal gland & + \\
Harderian gland & + to ++ \\
Ciliary necrves & +++ \\
\hline
\end{tabular}




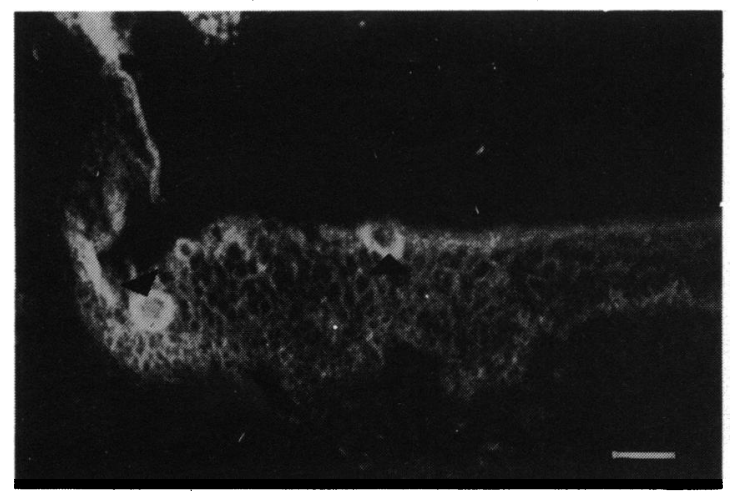

Fig. 3 Normal human conjunctiva. Note the reaction of fluoresceinated lectin with the stratified epithelium and goblet cells (arrows). Bar $=12 \mu \mathrm{m}$.

blood cells. The lectin to fluorescein ratio was 1:0.67 and the lectin concentration was $31 \mu \mathrm{g} / \mathrm{ml}$.

In our control experiments (i.e., neutralisation reaction) FITC conjugate was preincubated $(2 \mathrm{~h}$, $4^{\circ} \mathrm{C}$ ) in $0.2 \mathrm{M}$ solution of inhibitory sugar, D-gal NAc. The tissue sections were brought down to distilled water in the conventional way and then incubated for one hour at $37^{\circ} \mathrm{C}$ in the same solution. Fluorescence in these sections was completely eliminated when compared with sections exposed to the conjugate without the inhibitory sugar. Additional experiments were performed to determine whether or not the specificity of the lectin for sites in ocular tissues was altered because of conjugation with FITC. Tissue sections were treated with FITC-lectin conjugate to which various concentrations of the corresponding unlabelled lectin had been added. In each instance the addition of unlabelled lectin at appropriate concentrations caused a uniform decrease in the overall intensity of fluorescence but did not alter the pattern of fluorescence. These observations suggest that labelled and unlabelled lectin compete for the same sites in ocular tissues and thus support the view that conjugation of lectin to FITC does not alter its specificity. Sections were also exposed to $0 \cdot 1 \mathrm{M}$ FITC in $0 \cdot 1 \mathrm{M}$ phosphate buffered saline to exclude any non-specific binding, and $1 \%$ aqueous osmium tetroxide was used for one to two minutes to quench autofluorescence. Stained sections were examined under an epifluorescence microscope equipped with FITC interference filter.

\section{Results}

Absolute methanol was found to be the most suitable fixative. The results obtained are summarised in Tables 1 and 2 . The designations used in these tables to indicate fluorescence intensities (i.e.,,+++ , etc.) were arrived at by comparing the reaction intensity of the conjugate with the control specimens containing the appropriate inhibitory sugar.

Cornea and conjunctiva. Sections of human and rat cornea treated with FITC-labelled soybean lectin showed strong (pericellular and cytoplasmic) fluorescence of the epithelium, particularly its superficial layers; in rabbits, however, the strongest reaction was present in the basal epithelial layer (Fig. 2). Corneal stroma was only weakly fluorescent, but Descemet's membrane and the endothelium were strongly reactive. The conjunctival epithelium and the goblet cells showed strong pericellular and diffuse cytoplasmic fluorescence respectively (Fig. 3); only weak fluorescence was seen in the sclera.

The uvea. The pigment epithelium of the iris along
Fig. 4 Normal rabbit ciliary body. The reaction is chiefly in the non-pigmented epithelium (arrows) and in the blood vessels (b) $B a r=18 \mu \mathrm{m}$.

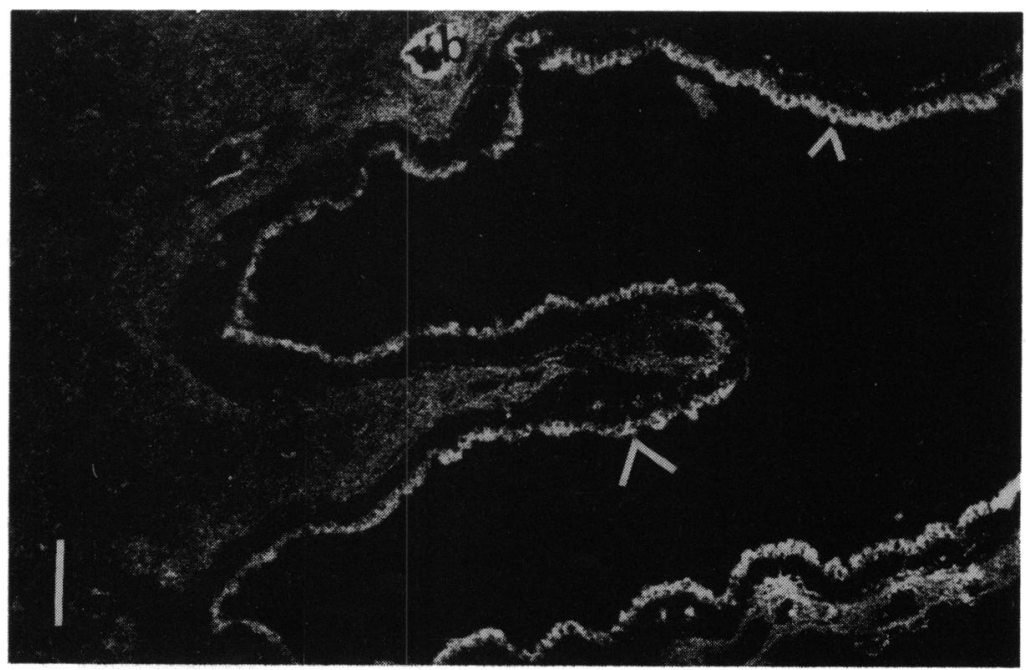




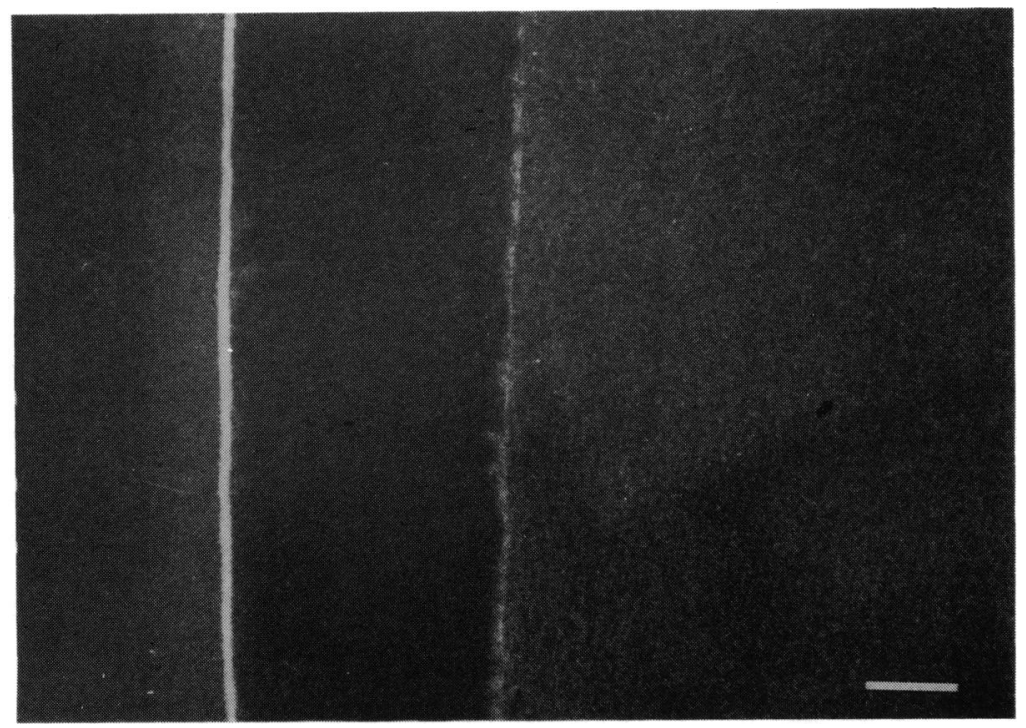

Fig. 5 Normal rabbit lens stained with fluorescein-labelled soyabean lectin. A weak reaction with the lens capsule but a very strong reaction with the lens epithelium is recorded. Bar $=18 \mu \mathrm{m}$.

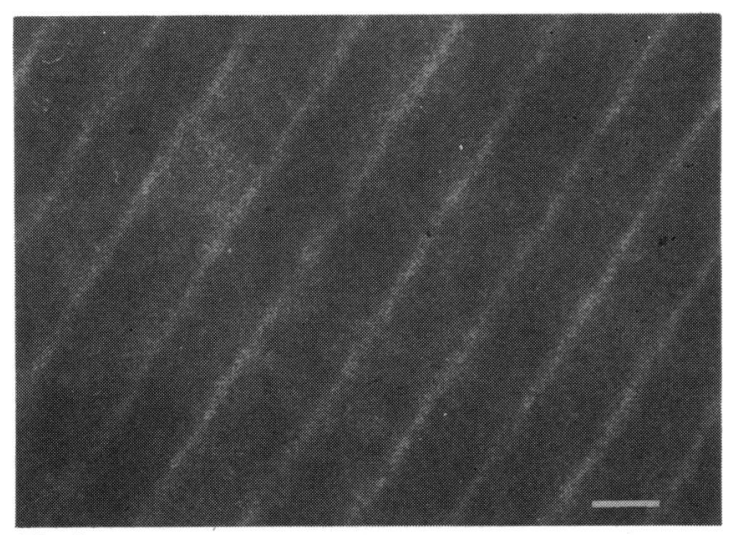

Fig. 6

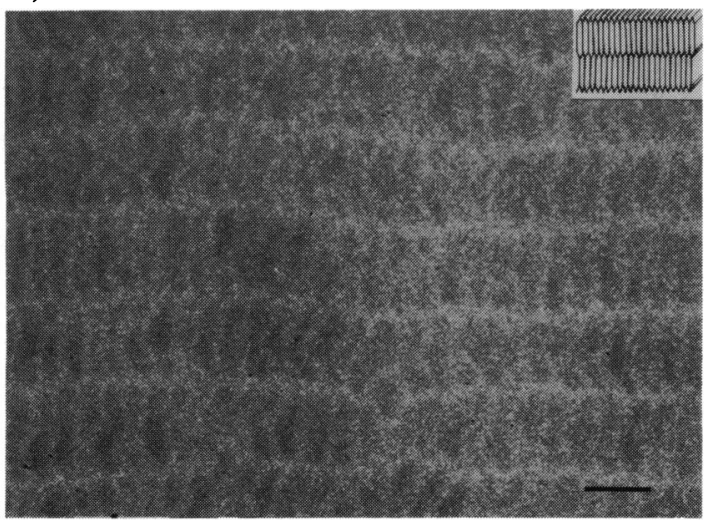

Fig. 7

Figs. 6 and 7 The lens cortex cut at various angles to show lens fibres; a moderate fluorescence is present between lens fibres in the region of interlocking junctions. Bar $=6 \mu \mathrm{m}$. with the dilator pupillae showed negligible fluorescence, but the ciliary epithelium was strongly fluorescent. Although the stroma showed weak fluorescence, the blood vessels were strongly fluorescent (Fig. 4). The choroid, apart from blood vessels, was unremarkable.

Trabecular meshwork. In contrast to the corneal endothelium, the meshwork cells showed only negligible fluorescence.

The lens. The zonule and the zonular lamellae were non-fluorescent. The capsule was only weakly fluorescent, but the lens epithelium showed a very strong fluorescence (Fig. 5). The rectangular or hexagonal cells of the lens cortex as seen in cross-section had a fairly homogeneous but weak cytoplasmic fluorescence. A rather strong reaction was present, however, along the sides of the hexagon where the interlocking processes of lens fibres are found (Figs. $6,7)$.

The retina. The internal limiting membrane and the nerve fibre layer showed no reactivity, but there was a weak reaction in the ganglion cell layer. The internal plexiform layer, internal nuclear layer, and the external plexiform layer similarly showed no fluorescence. The outer retina consisting of the photoreceptors, the pigment epithelium, and the associated Bruch's membrane showed, however, a very strong reaction (Figs. $8 \mathrm{a}, \mathrm{b}, \mathrm{c}$ ); the orbital portion of the optic nerve showed only moderate fluorescence.

Ocular adnexa. Extraocular muscles showed moderate to very strong staining reaction (Fig. 9). The epidermis, the hair follicles, and the blood vessels in the upper and lower eyelids showed strong fluorescence (Figs. 10, 11); Meibomian gland, 


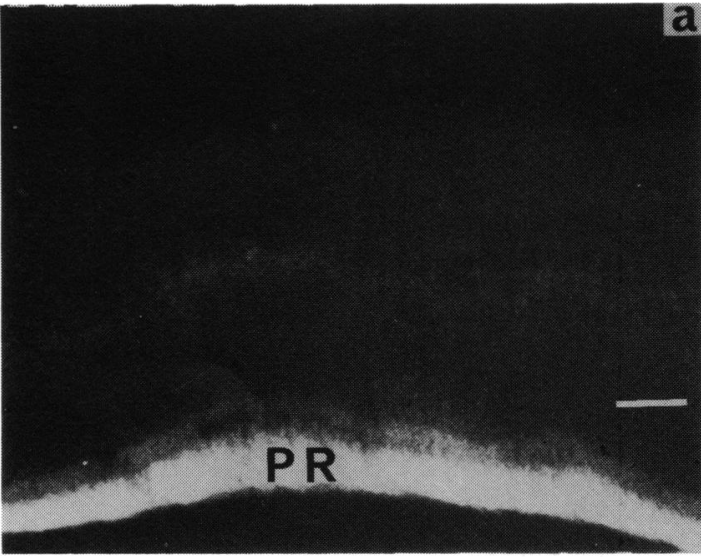

Fig. 8a

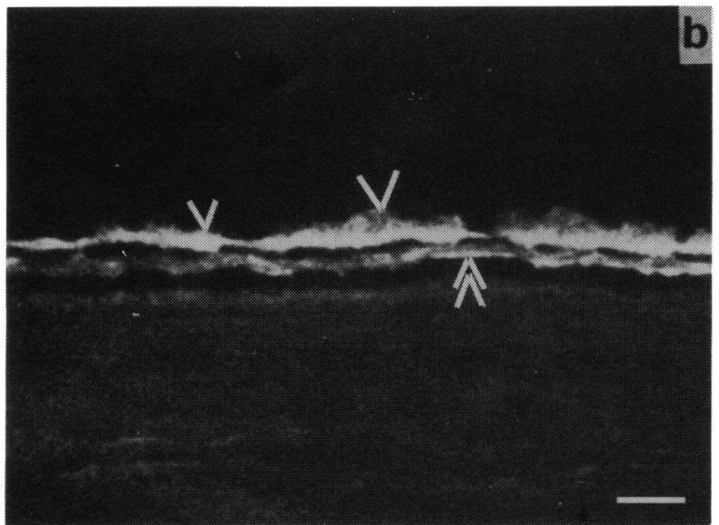

Fig. $8 \mathrm{~b}$

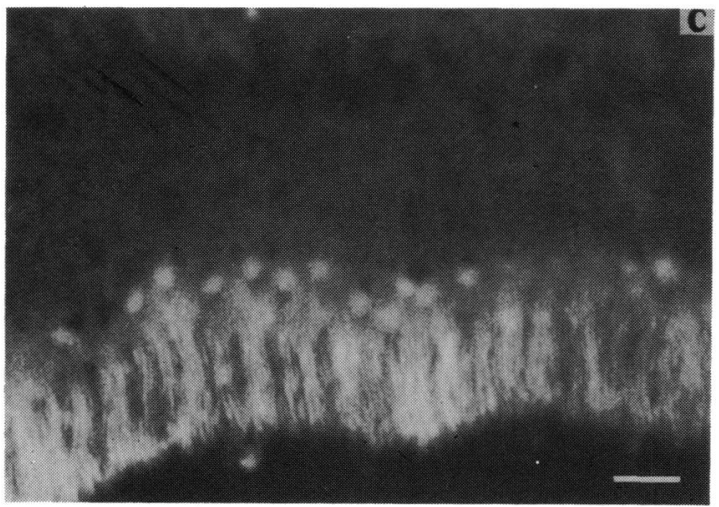

Fig. 8c

Fig. 8a, b, c Normal rabbit retina. The external retina, i.e., the photoreceptors (PR), the pigment epithelium (arrows), and fluorescence. Bars $(\mathrm{a}, \mathrm{b})=18 \mu \mathrm{m},(\mathrm{c})=10 \mu \mathrm{m}$.

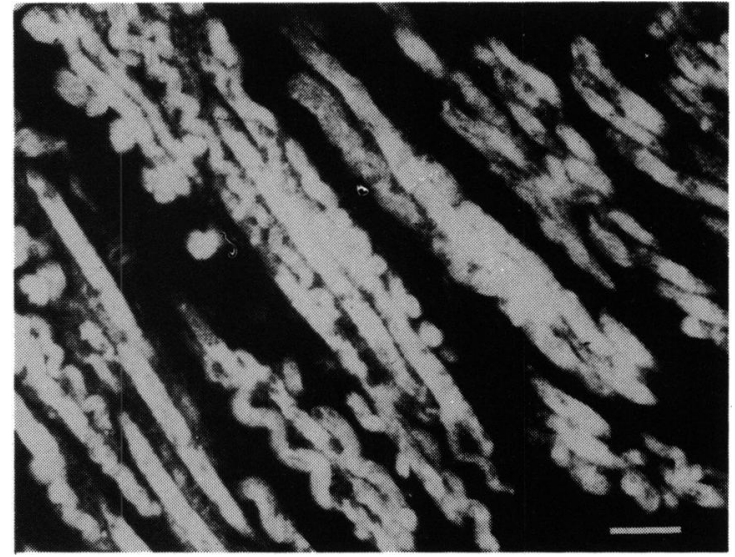

Fig. 9 Extrinsic muscle of rabbit eye showing varying degrees of fluorescence when reacted with soybean lectin. Bar $=18 \mu \mathrm{m}$.

sebaceous gland, and sweat gland (Fig. 12) were all moderately fluorescent. The ciliary nerve was strongly fluorescent, the optic nerve was moderately fluorescent, but the sciatic nerve which was used as a control showed a stronger fluorescence similar to that present in the ciliary nerve (Figs. 13a, b, c). Harderian and lacrimal glands were moderately fluorescent.

Ocular tumours. Since retinoblastomas arise in the sensory retina, sections of eyes with this tumour were treated with the same lectin. Whereas the photoreceptors gave the usual strong reaction, tumour cells apart from the feeding blood vessels were surprisingly non-fluorescent (Fig. 14). Areas of necrosis and haemorrhage showed, however, non-specific fluorescence.

Sections of malignant melanoma of the choroid were similarly non-fluorescent, but the overlying retinal pigment epithelium was strongly positive.

\section{Discussion}

The reactivity of soybean lectin with normal and neoplastic ocular tissues has not been so far fully investigated. The strong reaction in the superficial epithelial layers of human and rat corneae is comparable to that reported in the mucosal surface of the gastrointestinal tract. ${ }^{3}$ The intercellular fluorescence (Fig. 2) and the fluorescence of the basement membrane is in keeping with light microscopic studies in which PAS-positive material is demonstrable at these sites. ${ }^{45}$ Since the corneal stroma was only weakly fluorescent, it seems that the collagen and the intervening glycosaminoglycan have negligible amounts of D-gal NAc in addition to other carbohydrate residues reported before. ${ }^{\circ}$ Alternatively D-gal NAc if present may be located very close 


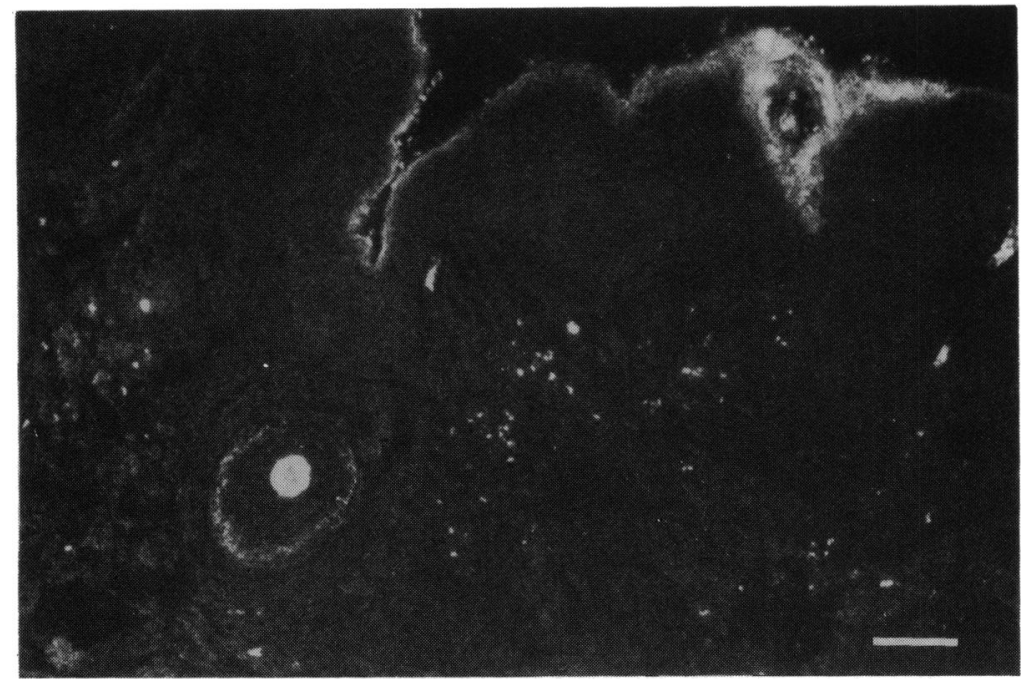

Fig. 10 The skin of human upper eyelid showing fluorescence of superficial epidermis, hair follicle, and small blood vessels.

to the molecule, as is the case with some other proteins ${ }^{78}$ rather than at the ends of the carbohydrate side chains, and thus be inaccessible to the FITClectin conjugates. The strong fluorescence of Descemet's membrane and corneal endothelium is in keeping with light microscopic studies in which the presence of glycoprotein is well documented. ${ }^{59}$ The conjunctival epithelium along with the goblet cells showed a strong reaction (Fig. 3), suggesting that these structures are rich in $\mathrm{N}$-acetyl-glactosamine residues.

Since the epithelial cells lining the ciliary body and the iris are embryologically related, the absence of staining in the latter is most surprising. It may perhaps be related to functional differentiation of

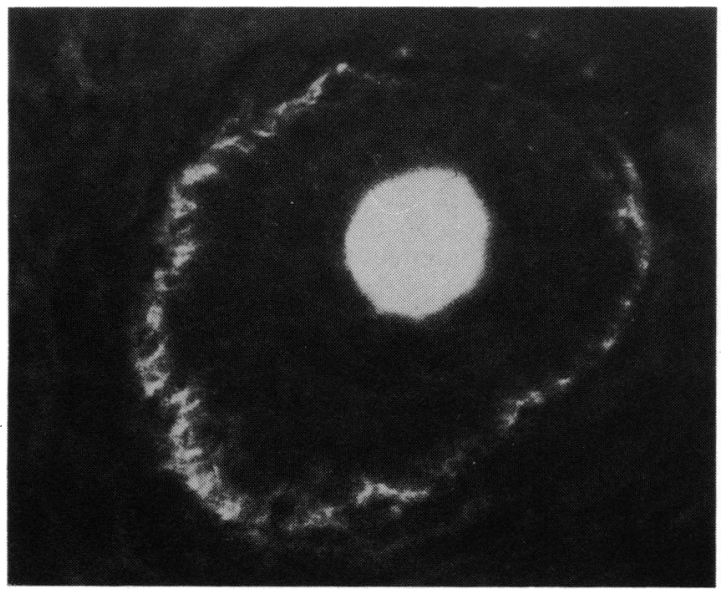

Fig. 11 Higher magnification of a hair follicle showing central fluorescence of hair shaft and peripheral fluorescence of epithelial cells. Bar $=6 \mu \mathrm{m}$. these two tissues, the ciliary epithelium being metabolically more active because of its involvement in aqueous humour production and elaboration of suspensory fibres of the lens.

Since the trabecular meshwork cells were negligibly fluorescent as compared with the corneal endothelial cells, it would seem that glycine max may be used as a marker for endothelial cells not only in tissue culture but also in histological preparations in conditions such as iris naevus syndrome, Chandler's endothelial dystrophy, and essential iris atrophy, in which the corneal endothelial cells supposedly grow over the trabecular meshwork and the adjoining surface of the iris. The strong fluorescence of photoreceptors may be due either to various glycoproteins within the visual cells ${ }^{10-13}$ or to the acid mucopolysaccharide mantle around the photoreceptors ${ }^{14}$ or perhaps both. Since the characteristic discs in the outer segment of photoreceptors are formed by infolding of the cell

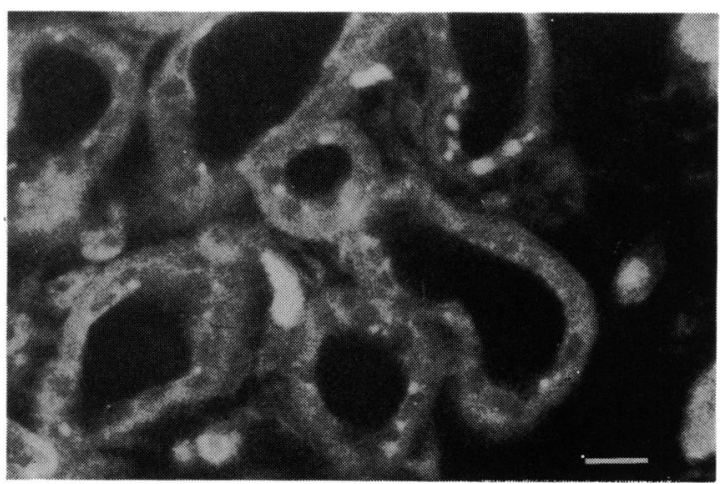

Fig. 12 Sweat gland in the human upper eyelid showing moderate fluorescence. Bar $=12 \mu$. 
Fig. 13 (a) Optic nerve was moderately fluorescent. (b) Ciliary nerve and (c) sciatic nerve (used as control) were strongly fluorescent. $\operatorname{Bars}(\mathrm{a})=25 \mu \mathrm{m},(\mathrm{b})=12 \mu \mathrm{m}$, (c) $=18 \mu \mathrm{m}$.

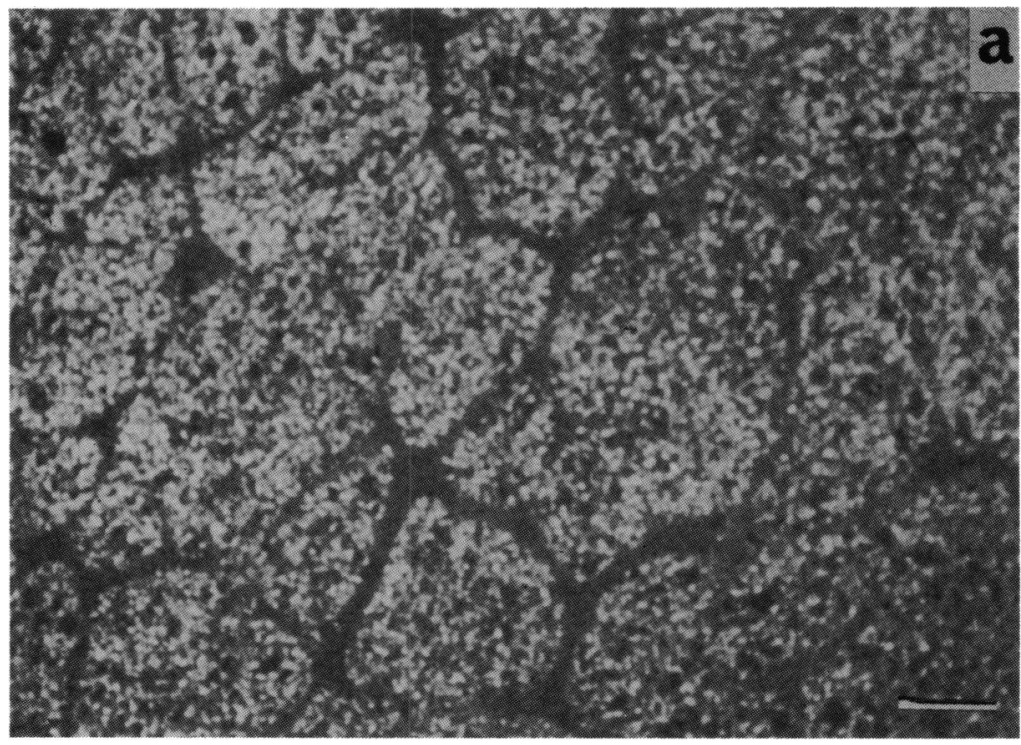

Fig. 13a

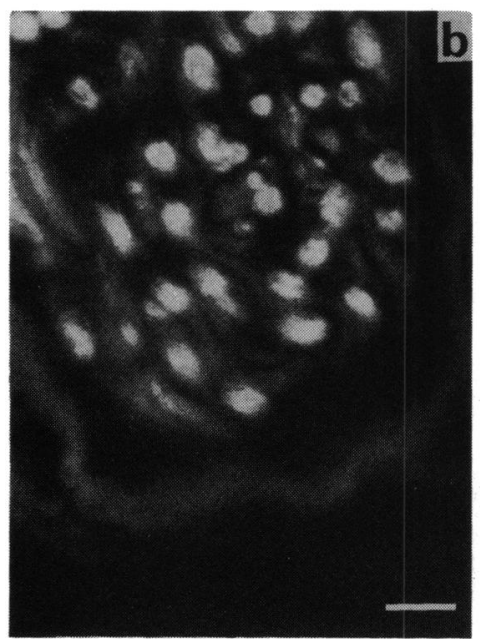

Fig. 13b

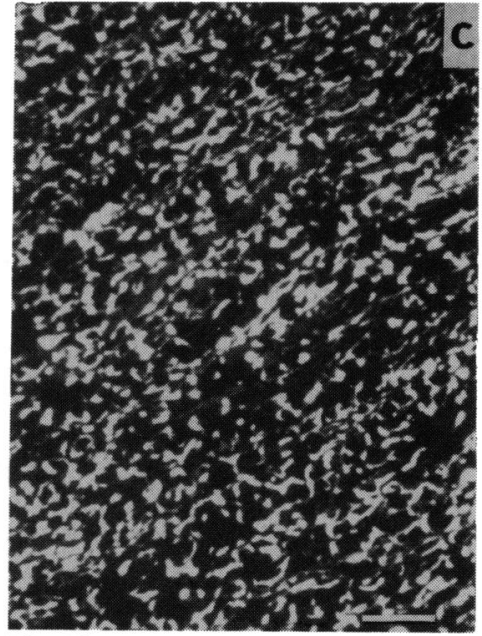

Fig. 13c membrane, it is conceivable that some of the fluorescence was due to displaced membrane associated saccharides. In a recent study ${ }^{15}$ it has been demonstrated that photoreceptors from dystrophic rats lack binding sites for various other lectins which avidly bind to normal visual cells. Whether this is true for glycine max is not known; we are currently investigating the role of the relevant saccharide in rod outer segment phagocytosis.

As compared with the ciliary nerves the optic nerve showed weaker fluorescence. This is of interest because it is known that these two nerves are differently myelinated. This phenomenon has not been reported before and needs further examination in view of the fact that peripheral nerve myelin is less effective in inducing autoimmune inflammation of the nervous system. It is concluded that D-gal NAc is widely distributed in ocular tissues, albeit in varying amounts, being most abundant in metabolically active sites such as the corneal epithelium and the endothelium, the ciliary and the lens epithelium, the photoreceptors, and the retinal pigment epithelium (Fig. 15).

Since retinoblastoma develops in the sensory retina and differentiates towards photoreceptors, we were surprised to find that the tumour cells did not 


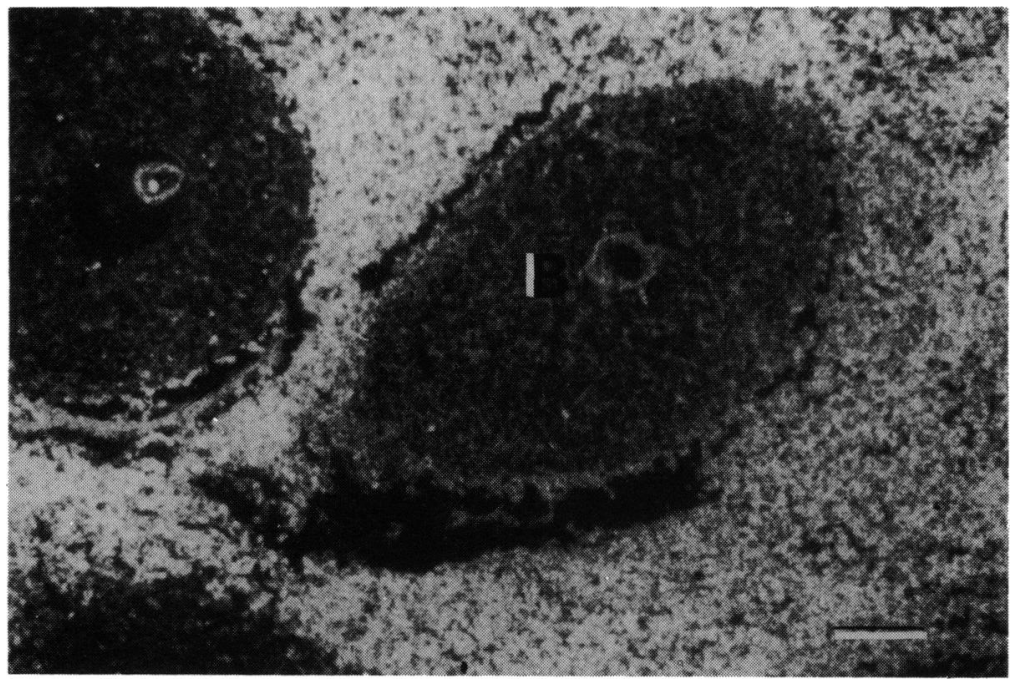

Fig. 14 Section of retinoblastoma showing no fluorescence of viable cells around blood vessels (B). Necrotic cells in the periphery showed non-specific binding. Bar $=12 \mu \mathrm{m}$.

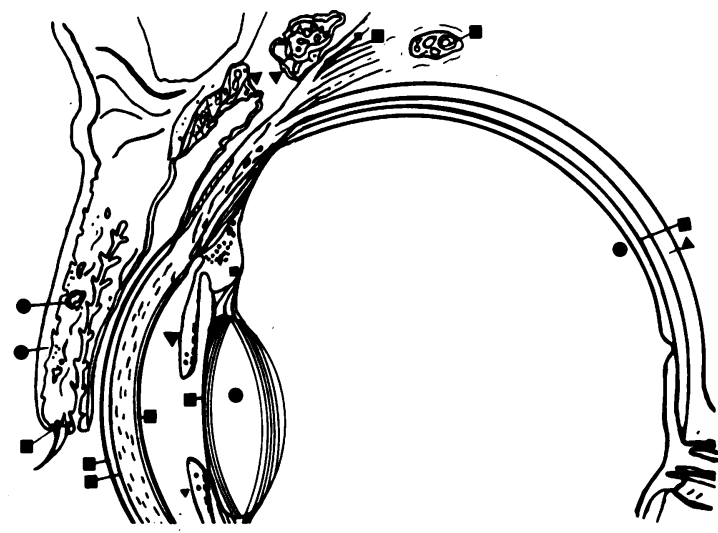

Fig. 15 Summary diagram of the distribution of $N$-acetyl-D-galactosamine (glycine max receptors) in ocular tissues. Strong fluorescence $\mathbf{D}$. Moderate fluorescence $\mathbf{0}$ Weak fluorescence $\mathbf{\Delta}$.

react with the lectin under study. As the differences in the cell membrane composition of normal and neoplastic tissues are well documented, ${ }^{16-20}$ it is possible that neoplastic change in the embryonic retina is associated either with loss of or a modification in the distribution of D-gal NAc. Alternatively there may have been an overall shortening in length of the saccharide sequences in surface glycoproteins of retinoblastoma cells as is known for other malignant cells. ${ }^{1620}$

The authors thank Professor A Garner and Dr I Grierson for their advice and stimulating discussion. Appreciation is also extended to Miss K Betts and Mrs P Goodwin for typing the manuscript.
References

1 Crumpton MJ, Owens RJ, Gallagher CJ, Davies AA. The cell surface and its metabolism. $J$ Pathol 1983; 141: 235-48.

2 Stoddart RW, Collins RD, Jacobson W. Lectin staining of carbohydrates of hacmic cell. J Pathol 1980; 313: 321-32.

3 Buck CA, Fuhrer JP, Soslau G, Warren L. Membranc-glycopeptides from subcellular fractions of control and virustransformed cells. J Biol Chem 1974; 249: 1541-50.

4 Bhavanandan VP, Davidson EC. Mucopolysaccharides associated with nuclei of cultured mammalian cclls. Proc Natl Acad Sci USA 1975; 726: 2032-6.

5 Leblond CP. Distribution of periodic acid-rcactive carbohydrates in the adult rat. $J$ Anat $1950 ; 86: 1-8$.

6 Liener IE, Wada S. Chemical composition and end groups of the soybean haemagglutinin. J Biol Chem 1958; 233: 395-402.

7 Spiro RG. Glycoproteins: structure, metabolism and biology $N$ Engl J Med 1963; 269: 566-71.

8 Steinemann A, Stryer L. Accessibility of the carbohydrate moiety of rhodopsin. Biochemistry 1973; 12: 1499-506.

9 Moore JC, Tiffany JM. Human ocular mucus origins and preliminary characterisation Exp Eye Res 1979; 29: 291-301.

$10 \mathrm{Nir}$ I. Visualization of intraccllular concanavalin $\mathrm{A}$ binding sites in retinal photoreceptors. J Histochem Cytochem 1978; 26: 822-8.

11 O'Brien BJ. Rhodopsin as a glycoprotcin, a possible rolc for the oligosaccharide in phagocytosis. Exp Eye Res 1983; 23: 127-37.

12 Plantner JJ, Kean EL. Carbohydrate composition of bovine rhodopsin. J Biol Chem 1976; 251: 1548-59.

13 Uehara F, Samesharina M, Takashi M, Ohba N. Localization of fluorescence-labelled lectin binding sites on photoreccptor cells of the monkey retina. Exp Eye Res 1983; 36: 113-23.

14 Zimmerman LE, Eastham AB. Acid mucopolysaccharide in the retinal pigment cpithelium and visual cell layer. Am J Ophthalmol 1959; 47: 488-99.

15 McLaughlin BJ, Wood JG. The localization of Icctin binding sites on photoreceptor outer segments and pigment cpithelium of dystrophic retinas. Invest Ophthalmol Visual Sci 1980; 19: $728-42$.

16 Scla BA, Lis H, Sharon N. Sachs L. Different locations of carbohydratc-containing sites in the surface membrane of normal 
and transformed mammalian cells. J Membr Biol 1970; 3: 267-79.

17 Stoddart RW, Collins RD, Jacobson W. The microanalysis of saccharide structures of normal and ncoplastic tissues. Biochem Soc Trans 1974; 2: 481-3.

18 Warren L. The malignant cell and its membranes. Ann J Pathol 1974; 77: 69-76.
19 Goldberg AH, Ycoman LG, Busch H. Chromatin-associated glycoproteins of normal rat liver and Novikoff hepatoma ascites cells. Cancer Res 1978; 38: 1052-8.

20 Nicolson GL, Blaustcin J. The interaction of Ricinus communis agglutinin with normal and tumour cell surfaces. Biochem Biophys Acta 1972; 266: 543-7. 